\title{
Visibility and air pollution
}

\author{
J. G. Watson \& J. C. Chow \\ Desert Research Institute, Reno, NV, USA
}

\begin{abstract}
Haze is caused by the scattering and absorption of visibility light by particles and gases. Light is an electromagnetic wave, and just as a plane water wave is deflected by a barrier from its original direction, light waves are scattered when they encounter particles and gas molecules that are approximately the same size as the light's wavelength. The sky is blue because particle-free air also scatters light, but the gas molecules are so small that they scatter the shorter wavelength blue light more than they scatter the longer wavelength red light. Total extinction $\left(b_{\text {ext }}\right)$, expressed in inverse megameters $\left(\mathrm{Mm}^{-1}\right)$, is multiplied by the distance between an observer and a target to indicate the amount of light removed from the site path by scattering and absorption by particles and gases, and is the most common measurement used to quantify visibility. Total extinction does not take into consideration light scattered into the sight path that further reduces the target's contrast (ratio of light transmitted from the target to the light transmitted from the horizon). Defining natural conditions is a scientific challenge. Annual average estimates are currently in use, but these will eventually need to be made more event-specific. Wildfires, dust storms, and other natural events will affect visibility on a case-by-case basis. Transport from outside of provincial and national boundaries needs to be considered because this is largely beyond the control of authorities.
\end{abstract}

Keywords: haze, visibility, PM.

\section{Introduction}

This paper provides an overview of urban and regional haze and its relationships to other pollutants. It describes the nature and causes of poor visibility, identifies relationships to fine particles and other pollutants, explains regulatory approaches to local and regional haze, and discuses relevance to other regional 
and global pollution problems. It is based on recent reviews of regional haze [1-3] that provide greater detail and references to a larger array of published literature.

\section{Causes of haze}

Haze is caused by the scattering and absorption of visibility light by particles and gases. Light is an electromagnetic wave; just as a plane water wave is deflected by a barrier from its original direction, light waves are scattered when they encounter particles and gas molecules that are approximately the same size as the light's wavelength. The sky is blue because particle-free air also scatters light, but the gas molecules are so small that they scatter the shorter wavelength blue light more than they scatter the longer wavelength red light.

\section{Measures of haze}

Total extinction $\left(b_{\text {ext }}\right)$, expressed in inverse megameters $\left(\mathrm{Mm}^{-1}\right)$, is multiplied by the distance between an observer and a target to indicate the amount of light removed from the site path by scattering and absorption from particles and gases. $b_{\text {ext }}$ is the most common metric used to quantify visibility, but it does not consider light scattered into the sight path that further reduces the target's contrast (ratio of light transmitted from the target to the light transmitted from the horizon). The human eye is also sensitive to the spacing of objects, such as trees and rocky strata, and the observer may perceive texture better even as his or her position becomes more distant with respect to the target.

Visual range, which is approximately $4 / b_{\text {ext }}$, is often used to express the maximum distance at which a target can be discriminated from its background. The deciview, $d v=10 \ln \left(b_{\text {ext }} / 10\right)$, has been adopted for tracking improvements in regional haze in the United States. Twenty-four hour averages of "dry" light scattering are often correlated with $\mathrm{PM}_{2.5}$ concentrations.

The United States uses a chemical extinction budget to estimate the deciviews that track regional haze over long periods. Figure 1 shows the network of measurement locations that is used to obtain $\mathrm{PM}_{2.5}$ mass and elemental compositions. Chemical extinction $\left(b_{\text {ext }}\right)$ is estimated as:

$b_{\text {ext }}\left(\mathrm{Mm}^{-1}\right)=\Sigma$ dry extinction efficiency $\left(\mathrm{m}^{2} / \mathrm{g}\right) \times$ humidity modifier $\times$ species concentration $\left(\mu \mathrm{g} / \mathrm{m}^{3}\right)=3 \mathrm{f}(\mathrm{RH}) \times\left(\mathrm{NH}_{4}\right)_{2} \mathrm{SO}_{4}+3 \mathrm{f}(\mathrm{RH}) \times \mathrm{NH}_{4} \mathrm{NO}_{3}+4 \times$ Organics $+10 \times$ Soot $+1 \times$ Soil $+0.6 \times$ Coarse Mass $+10 \times$ Clear Air Scattering

where:

$f(R H)=$ extinction efficiency increase with RH.

The dry extinction efficiencies depend on particle size distributions and chemical compositions and can span a range of more than a factor of two for different distributions that might occur in the atmosphere. These efficiencies also depend on the complex mixing of particles with different compositions. 
The soot fraction does not attain the $10 \mathrm{~m}^{2} / \mathrm{g}$ dry scattering in the above formula, but this approximates what is found in nature. This occurs because the absorption efficiency of elemental carbon (or soot) is much higher when it is coated with a layer of sulfate or organic carbon than when it is present as a separate particle. There can be large discrepancies, and large uncertainties, in $\mathrm{f}(\mathrm{RH})$ when $\mathrm{RH}$ exceeds $90 \%$. In spite of the uncertainties in creating chemical (reconstructed) extinction budgets, they reproduce sight path and point measurements fairly accurately for the 24-hour particle samples taken at U.S. parks and monuments, as shown by Chow et al. [1].

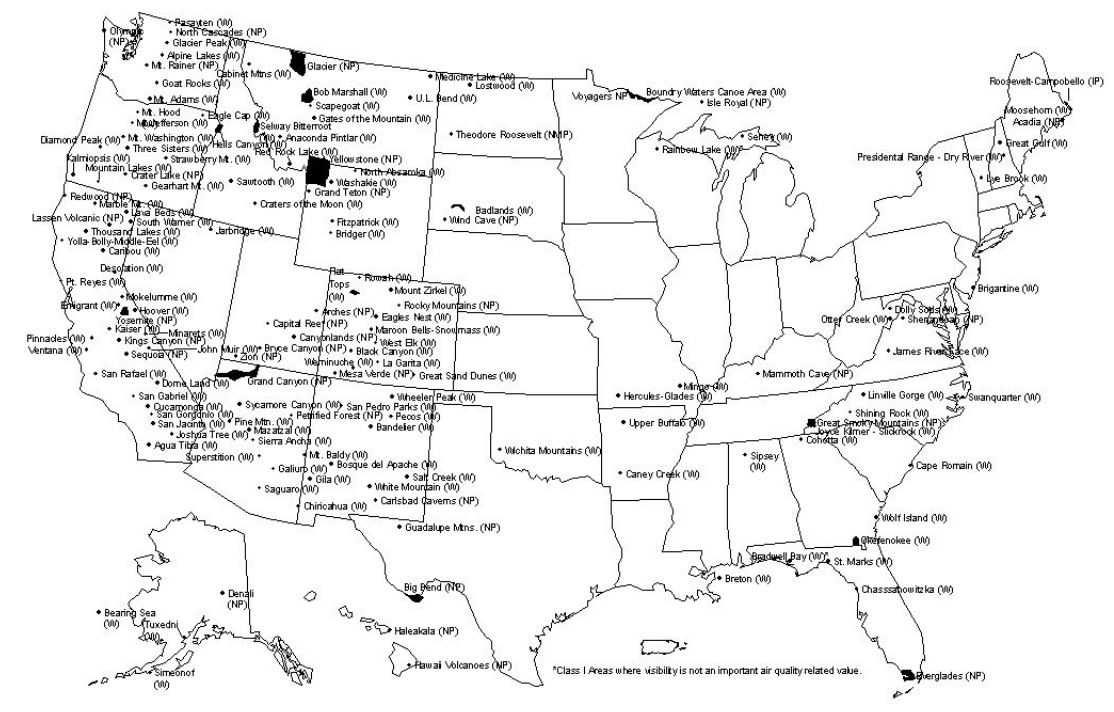

Legend:
$N P$ National Park
$W W=$ Valldemess
$\mathbb{P}=$ r tremational Park

Figure 1: Sampling locations for the IMPROVE (Interagency Monitoring of PROtected Visual Environments) that are located in U.S. National Parks and Wilderness areas. Data from this and other PM networks are available at http://vista.cira.colostate.edu/views/.

The value of the chemical extinction is that it can focus control efforts on the chemical components, and their sources, that are the major causes of the poor visibility. Shenandoah, Great Smoky Mountain, and Acadia national parks in the eastern U.S. have poor visibility caused mostly by sulfate concentrations. Other parks in the western U.S. have better visibility, but it is more evenly distributed among a number of chemical components. The implication is that sulfur dioxide reductions will be the most effective controls in the east, while many sources will need to be targeted to improve western visibility. A large decrease in extinction may not cause a large change in the deciview metric that better represents how people will perceive just noticeable changes in haze. Nearly 
$30 \mathrm{Mm}^{-1}$ corresponds to a one deciview change when comparing Great Smoky Mountains with Shenandoah, but only a few $\mathrm{Mm}^{-1}$ change is perceptible between Bryce Canyon and Denali.

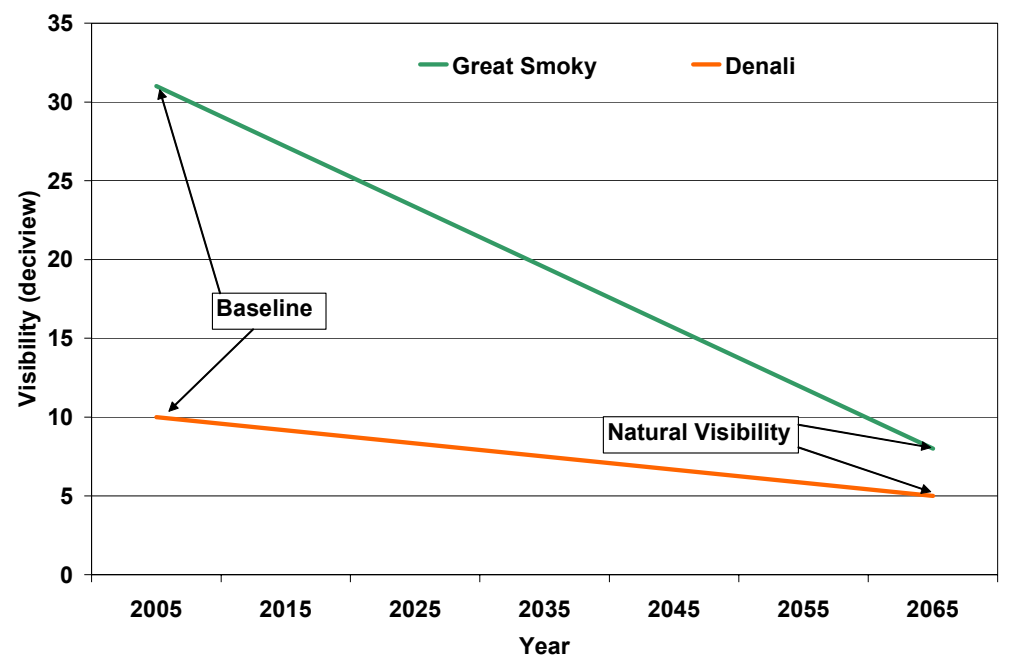

Figure 2: $\quad$ Example of visibility goals for Great Smoky Mountains and Denali National Parks in the U.S. The baseline is the average highest 20\% extinction for 2000 through 2004. Natural conditions are derived from annual average estimates of non-anthropogenic carbon, soil, sulfate, and nitrate concentrations. Natural conditions differ among regions owing to different natural sources (e.g., biogenic aerosol formation) and relative humidity.

\section{Improving visibility}

Reducing regional haze requires emission reductions that cross local, provincial, and international boundaries. The U.S. has established five regional planning organizations with different states as members to track progress toward natural background levels at 156 national parks and wilderness areas with measurements shown in Figure 1. At each of these areas, chemical extinction will be tracked for the next 60 years relative to a baseline for the poorest $20 \%$ of the days established by measurements between 2000 and 2004. A linear glide path toward natural visibility conditions, illustrated in Figure 2, will be used to determine progress that will be evaluated at ten year intervals. There are differences in the rate of progress depending on how poor the initial visibility is and what are considered to be natural conditions for an area. Defining natural conditions is a scientific challenge. Annual average estimates are currently in use, but these will eventually need to be made more event-specific. Wildfires, 
dust storms, and other natural events will affect visibility on a case-by-case basis. Transport from outside of the U.S. will also need to be considered because this is largely beyond the control of national authorities.

\section{Conclusions}

Among the most important topics that need further review and evaluation are: (1) practical methods for sampling and analyzing organic and elemental carbon; (2) scientific validity and practical requirements for integrating continuous particle monitoring technology into ongoing networks; (3) North American and global emissions from natural and anthropogenic sources; (4) satellite technology for tracking haze, emission sources, and pollution levels; (5) non-road emission source identification and estimation methods; (6) chemical markers for natural and anthropogenic sources; (7) air quality trend detection and tracking methods; and (8) integration of source and receptor models. Urban and regional haze is an important indicator of air pollution in many cities throughout the world. Quality of life and enjoyment of majestic vistas will improve only when serious emission reductions are undertaken to improve visibility. These have the added benefit of improving public health and reducing property damage due to excessive air pollution.

\section{References}

[1] Chow, J.C., Bachmann, J.D., Wierman, S.S.G., Mathai, C.V., Malm, W.C., White, W.H., Mueller, P.K., Kumar, N., \& Watson, J.G., 2002 Critical review discussion - Visibility: Science and regulation. J.Air Waste Manage.Assoc., 52(9), pp. 973-999, 2002.

[2] Watson, J.G. \& Chow, J.C., Clear sky visibility as a challenge for society. Annu.Rev.Energy Environ., 19pp. 241-266, 1994.

[3] Watson, J.G., Visibility: Science and regulation. J.Air Waste Manage.Assoc., 52(6), pp. 628-713, 2002. 